\title{
Multiple cavitating nodules in a renal transplant recipient
}

\author{
Sharla-Rae J Olsen MD, Mohit Bhutani MD
}

\begin{abstract}
S-RJ Olsen, M Bhutani. Multiple cavitating nodules in a renal transplant recipient. Can Respir J 2009;16(6):195-197.

Pulmonary nodules are common following solid organ transplantation and vary in etiology. Nodules with central cavitation are most likely to be of infectious origin in the post-transplant population. A novel presentation of post-transplant lymphoproliferative disorder manifesting as multiple cavitating pulmonary nodules is described. The patient, a 45-year-old female renal transplant recipient, presented with constitutional symptoms and a chest $\mathrm{x}$-ray showing multiple bilateral cavitating lesions. A computed tomography scan confirmed innumerable, randomly dispersed, cavitating nodules in the lung parenchyma. Multiple large hypodense lesions were identified in the liver and spleen. The appearance of the native and transplanted kidneys was normal. A liver biopsy identified an EpsteinBarr virus-negative, diffuse, large $B$ cell lymphoma. Repeat imaging after treatment with a cyclophosphamide, hydroxydaunorubicin, oncovin and prednisone/prednisolone regimen demonstrated dramatic resolution of all lesions. The present case represents a unique radiographic presentation of post-transplant lymphoproliferative disorder not previously reported in the literature.
\end{abstract}

Key Words: Cavitary; Nodule; PTLD; Pulmonary; Transplant

$\mathrm{P}$ ulmonary nodules, either solitary or multiple, are common following solid organ transplantation and have a variety of etiologies (Table 1). Nodules with central cavitation are most likely to be of infectious origin (1). We report a unique radiographic presentation of post-transplant lymphoproliferative disorder (PTLD) manifesting as multiple cavitating pulmonary nodules in a renal transplant recipient.

\section{CASE PRESENTATION}

A 45-year-old Caucasian woman with a history of renal transplantation for primary focal segmental glomerulosclerosis four years previously, presented to the emergency department with mid-epigastric pain. The patient had constitutional symptoms including fatigue, night sweats, intermittent low-grade fevers and a $4.5 \mathrm{~kg}$ weight loss during the previous two months. She had no history of cough or other respiratory symptoms, and a review of systems was otherwise negative. She had not travelled recently, and had no HIV risk factors or known exposure to tuberculosis. There were no recent changes to her medications, which included tacrolimus, mycophenolate mofetil, fosinopril, irbesartan and multivitamins.

Physical examination revealed a thin, afebrile patient with stable vital signs. She had mild epigastric tenderness to palpation and a positive Castell's sign, with no palpable spleen. Her liver span was enlarged at $16 \mathrm{~cm}$. The remainder of the examination was normal.

Initial laboratory results revealed a normocytic, normochromic anemia and mildly elevated creatinine that remained stable since her transplant. Other relevant laboratory work, including liver enzymes, was normal. A chest x-ray performed in

\section{De multiples nodules cavitaires chez un greffé du rein}

Les nodules pulmonaires sont courants après la greffe d'un organe solide, et leur étiologie varie. Les nodules dotés d'une cavité centrale sont plus susceptibles d'être d'origine infectieuse chez la population greffée. On décrit un cas de nouvelle présentation d'un trouble lymphoprolifératif après une greffe, se manifestant par de multiples nodules pulmonaires cavitaires. La patiente, une femme de 45 ans greffée du rein, a consulté en raison de symptômes constitutionnels et d'une radiographie pulmonaire révélant de multiples lésions cavitaires bilatérales. Une tomodensitométrie a confirmé la présence d'innombrables nodules cavitaires répartis aléatoirement dans le parenchyme pulmonaire. On a dépisté de grosses lésions hypodenses multiples dans le foie et la rate. L'apparence du rein indigène et du rein greffé était normale. Une biopsie rénale a permis de repérer un important lymphome à grosses cellules $\mathrm{B}$ diffus, négatif au virus d'Epstein-Barr. La reprise de l'imagerie, après le traitement à la cyclophosphamide, à l'hydroxydaunorubicine, à l'oncovine et à la prednisone et prednisolone, a révélé une résolution remarquable de toutes les lésions. Le présent cas constitue une présentation radiographique unique de trouble lymphoprolifératif après une greffe, jamais publiée auparavant.

\section{TABLE 1}

Differential diagnosis of multiple cavitating pulmonary nodules in the post-transplant setting

\begin{tabular}{lll}
\hline \multicolumn{2}{c}{ Infectious } \\
\hline Bacterial & Fungal & Viral \\
\hline Nocardia & Aspergillus & Cytomegalovirus \\
Mycobacteria & Cryptococcus & Other \\
Embolic & Other & \\
Other & & \\
Neoplastic & & \\
\hline Metastatic & &
\end{tabular}

Metastatic

Melanoma

Squamous cell

Bronchoalveolar

Other bronchogenic

Post-transplant lymphoproliferative disorder

Other

Wegener's granulomatosis

Rheumatoid arthritis

Pulmonary infarction

Data adapted from reference 11

the emergency room revealed multiple bilateral cavitating pulmonary nodules (Figure 1).

Given the history of the patient's immunosuppression, an infectious etiology was considered likely; subsequently, she was admitted to the pulmonary service under respiratory isolation. A computed tomography scan of the chest demonstrated hilar and mediastinal adenopathy as well as innumerable bilateral cavitating nodules in the lung parenchyma, varying in size from $5 \mathrm{~mm}$ 


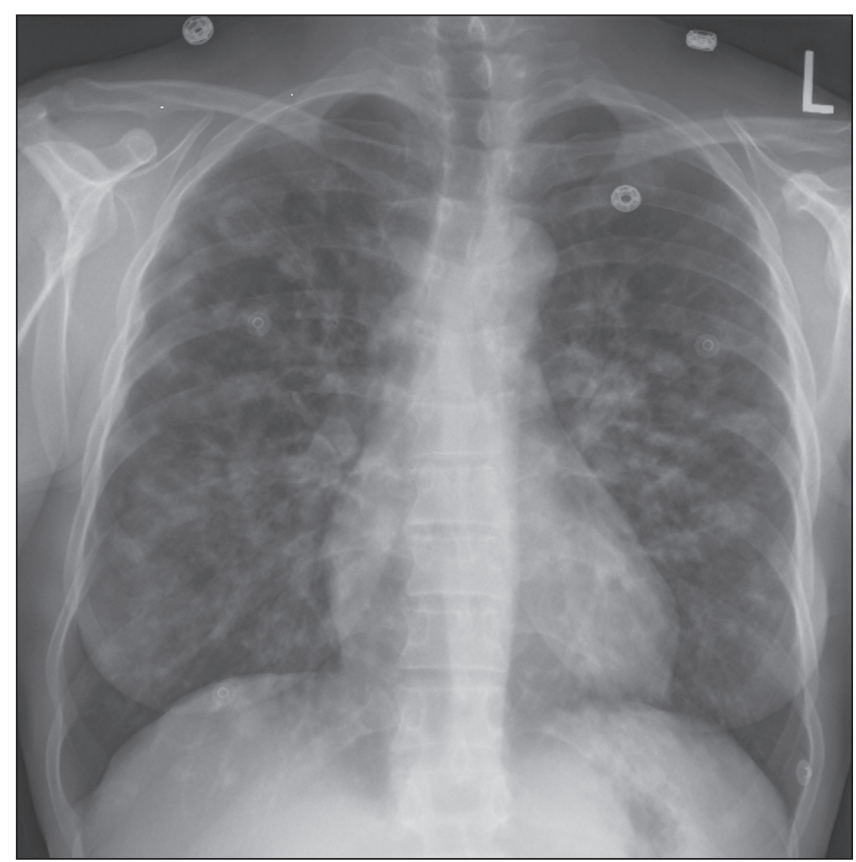

Figure 1) Chest x-ray at presentation showing multiple bilateral pulmonary nodules, many with central necrosis

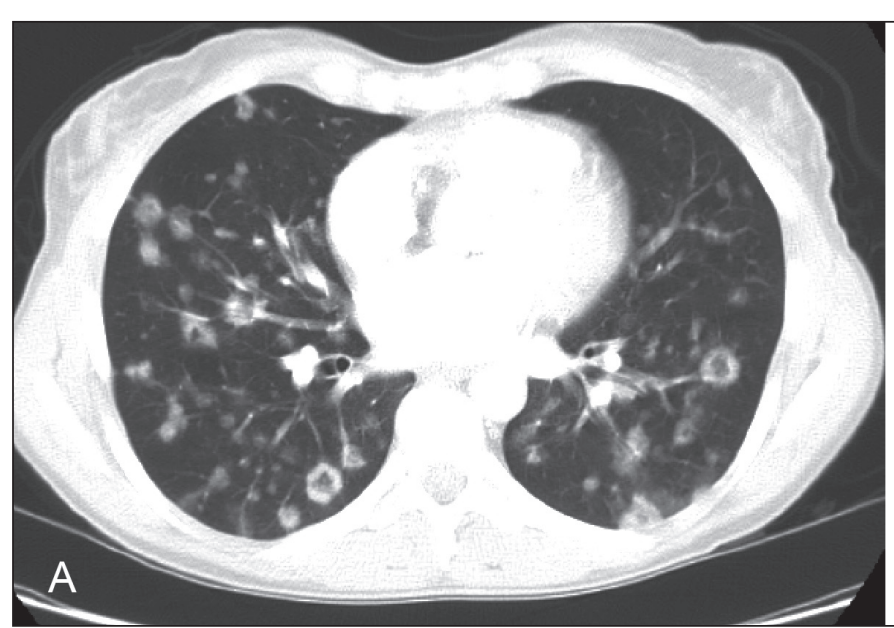

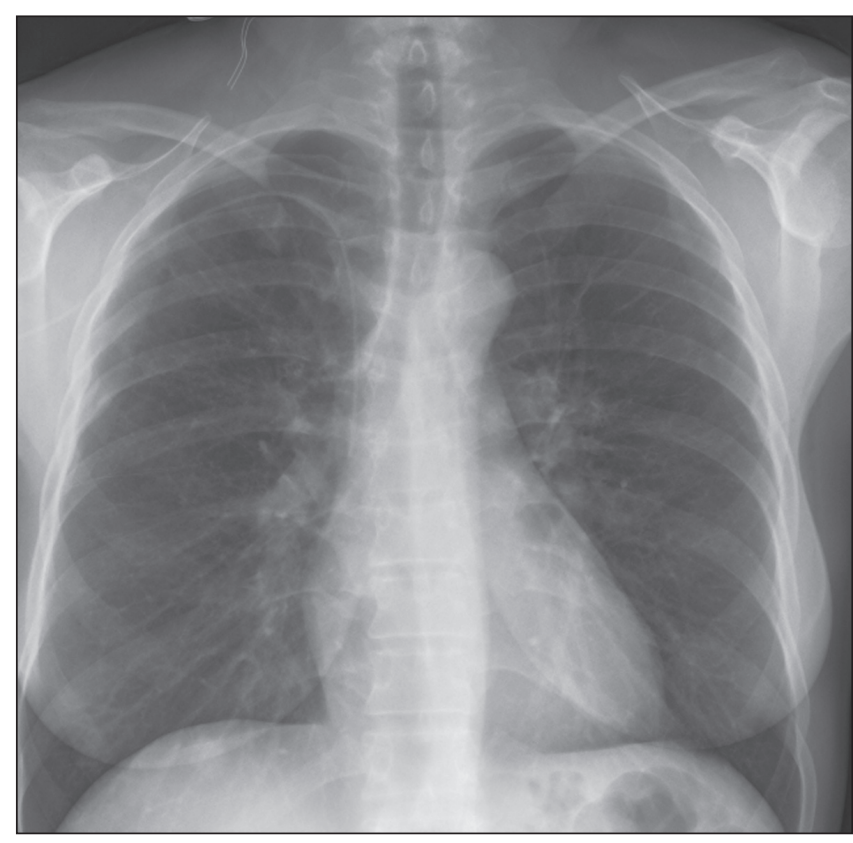

Figure 3) Chest x-ray after chemotherapy showing resolution of disease

Figure 2) A Computed tomography scan of the chest showing numerous cavitating pulmonary nodules dispersed randomly throughout both lung fields. B Computed tomography scan of the upper abdomen showing multiple hypodensities in the liver and spleen

to $25 \mathrm{~mm}$ (Figure 2A). Multiple, large hypodense lesions were identified in the liver and spleen (Figure 2B). The appearance of the native and transplanted kidneys was normal.

A core needle biopsy from one of the liver lesions revealed an Epstein-Barr virus (EBV)-negative, diffuse, large B cell lymphoma. This finding was confirmed on a subsequent bone marrow biopsy.

In keeping with treatment recommendations for PTLD, the immunosuppressives were reduced (mycophenolate mofetil was discontinued and the dose of tacrolimus decreased). However, the lesions did not respond; subsequently, a course of singleagent rituximab was attempted. This was also ineffective and the patient subsequently received eight cycles of cyclophosphamide, hydroxydaunorubicin, oncovin and prednisone/prednisolone chemotherapy. A chest x-ray and computed tomography scan performed three months later showed complete resolution of her disease (Figures 3 and 4).

\section{DISCUSSION}

We believe the present case illustrates a unique presentation of PTLD manifesting as multiple bilateral cavitating lung nodules - a finding that has not been previously reported in the literature.

The differential diagnosis of cavitating lung nodules in an immunocompromised patient is outlined in Table 1 . A recent retrospective review (1) of pulmonary nodules in 55 solid organ transplant recipients found that $60 \%$ had multiple nodules, the majority of which were infectious in etiology. Thirteen per cent of all nodules were cavitary; however, the authors did not specify if any were due to PTLD.

PTLD is a severe complication of organ transplantation, occurring in only $1 \%$ of renal transplant recipients. It encompasses a spectrum of pathological entities ranging from benign polyclonal B cell hyperplasia to malignant monoclonal nonHodgkins lymphoma. Most are EBV-related B cell neoplasms; 
however, tumours of T cell origin and EBV-negative tumours are well documented $(2,3)$. In renal transplant recipients, chronic immunosuppression confers an 11.8-fold increase in the risk of malignant lymphomas over a 10-year period compared with nontransplanted controls (4).

The radiographic findings of PTLD most commonly involve the abdomen, often with hypoattenuating liver nodules, adenopathy and splenomegaly, similar to our patient (5). Twenty per cent will involve the renal allograft and 38\% will involve multiple sites (2). Pulmonary parenchymal PTLD is more common in lung transplant recipients but has been previously reported in renal transplants $(6,7)$. The most common pulmonary manifestation of PTLD is multiple, well-defined, homogeneous lung nodules with a basal predominance $(1,5,8,9)$. An extensive literature search resulted in only one other documented case of a cavitary lung nodule in a renal transplant recipient due to PTLD (1).

The treatment of PTLD depends, in part, on the pathological diagnosis. In cases of early-onset polyclonal disease, reduction of immunosuppressive therapy is the first-line intervention. This must be balanced against the risk of allograft rejection. In tumours that fail to respond to reduction in immunosuppression, or in aggressive non-Hodgkins lymphomas (such as our patient), single-agent rituximab or combination chemotherapy and, in some cases, radiation or surgery may be indicated (10). Overall survival is $61 \%$ at five years, with the best prognosis being in localized, early polyclonal disease (2).

\section{CONCLUSION}

Our case identifies a unique radiographic presentation of a severe complication of solid organ transplantation. Although not common, PTLD should be considered in the differential diagnosis of cavitary lung nodules in transplant recipients.

\section{REFERENCES}

1. Dodd GD III, Ledesma-Medina J, Baron RL, Fuhrman CR. Post transplant lymphoproliferative disorder: Intrathoracic manifestations. Radiology 1992;184:65-9.

2. Caillard S, Lelong C, Pessione F, Moulin B. (French PTLD Working Group). Post transplant lymphoproliferative disorders occurring after renal transplantation in adults: Report of 230 cases from the French registry. Am J Transplant 2006;6:2735-42.

3. Capello D, Rossi D, Gaidano G. Post transplant lymphoproliferative disorders: Molecular basis of disease histogenesis and pathogenesis. Hematol Oncol 2005;23:61-7.

4. Opelz G, Dohler B. Lymphomas after solid organ transplantation: A collaborative transplant study report. Am J Transplant 2004;2:222.

5. Burney K, Bradley M, Buckley A, Lyburn I, Rye A, Hopkins R. Post transplant lymphoproliferative disorder: A pictorial review. Austral Radiol 2006;50:412-8.
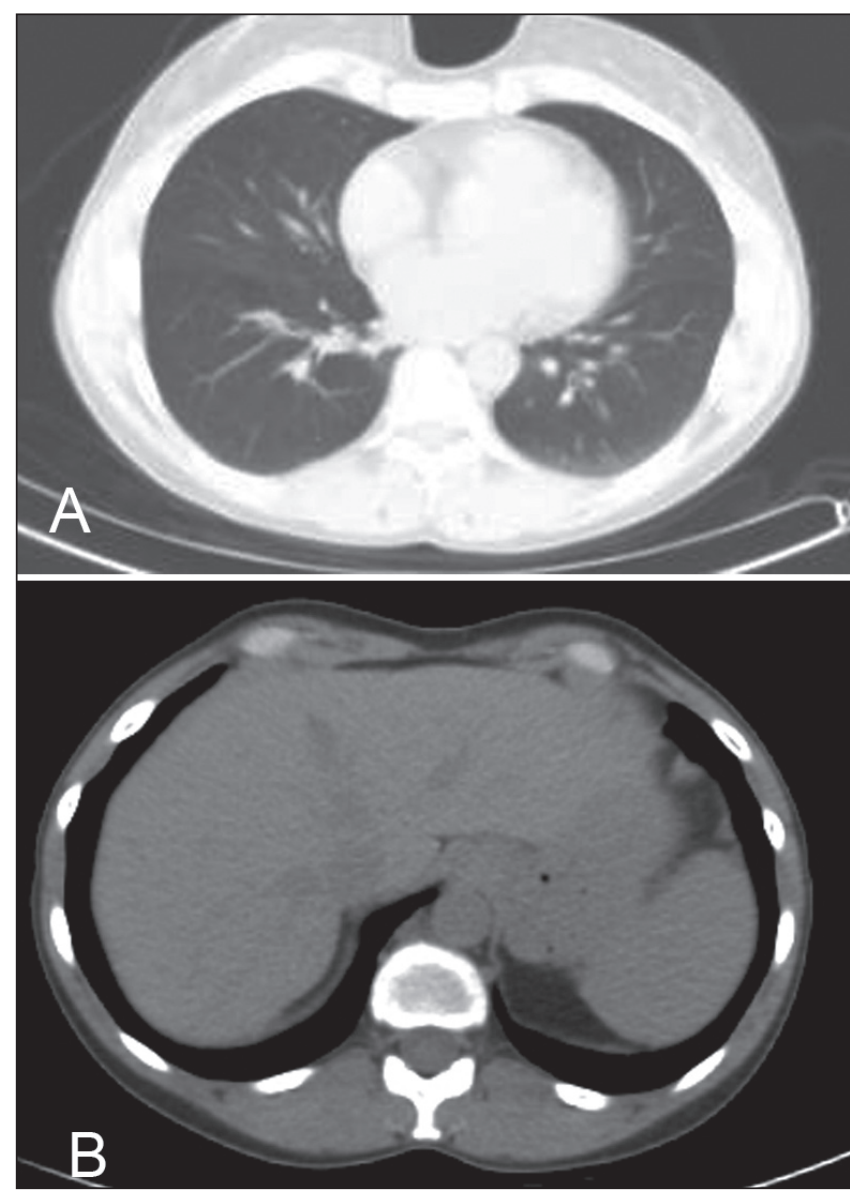

Figure 4) A Computed tomography scan of the chest showing clearing of all nodules at three months following chemotherapy. B Views of the upper abdomen also show dramatic resolution of the liver and splenic lesions

6. Halkos ME, Miller JI, Mann KP, Miller DL, Gal AA. Thoracic presentations of lymphoproliferative disorders. Chest 2004;126:2013-20.

7. Foroncewicz B, Mucha K, Usiekniewicz J, et al. Post transplant lymphoproliferative disorder of the lung successfully treated with surgery. Transplant Proc 2006;38:173-6.

8. Collins J, Muller NL, Leung AN, et al. Epstein-Barr virus associated lymphoproliferative disease of the lung: CT and histologic findings. Radiology 1998;208:749-59.

9. Carignan S, Staples CA, Muller NL. Intrathoracic lymphoproliferative disorders in the immunocompromised patient: CT findings. Radiology 1995;197:53-8.

10. Frey NV, Tsai DE. The management of post transplant lymphoproliferative disorder. Med Oncol 2007;24:125-36.

11. Copp DH, Godwin JD, Kirby KA, Limaye AP. Clinical and radiologic factors associated with pulmonary nodule etiology in organ transplant recipients. Am J Transplant 2006;6:2759-64. 


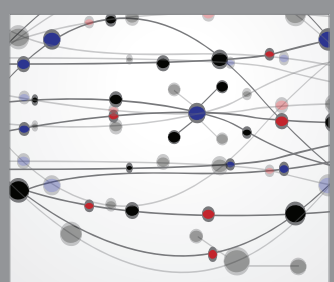

The Scientific World Journal
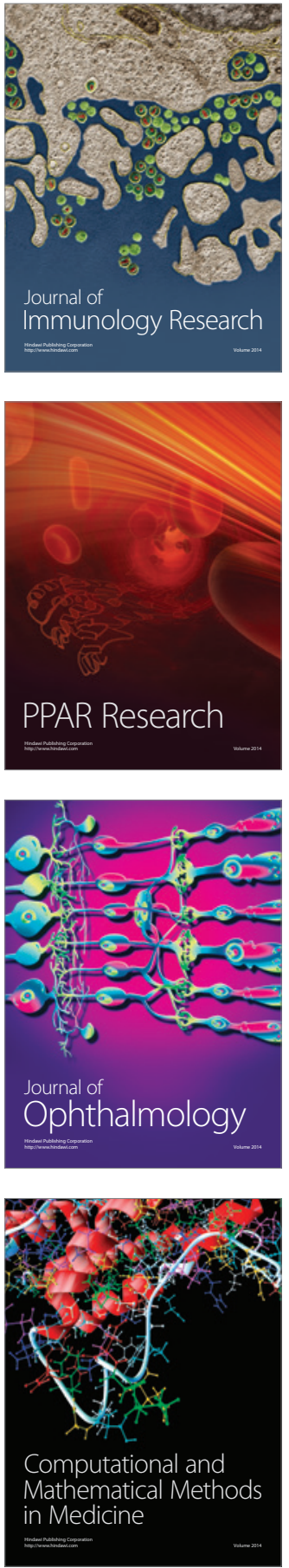

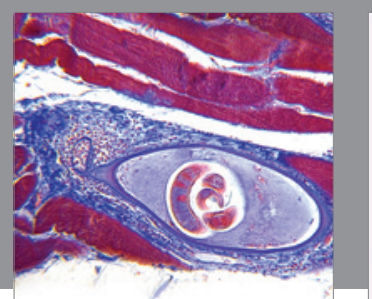

Gastroenterology Research and Practice

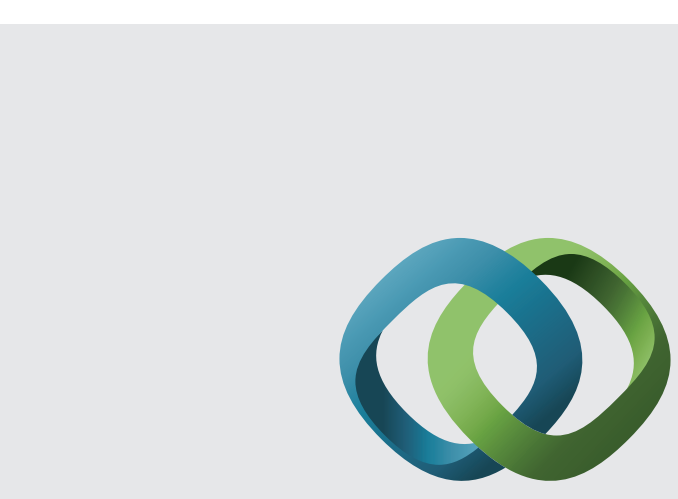

\section{Hindawi}

Submit your manuscripts at

http://www.hindawi.com
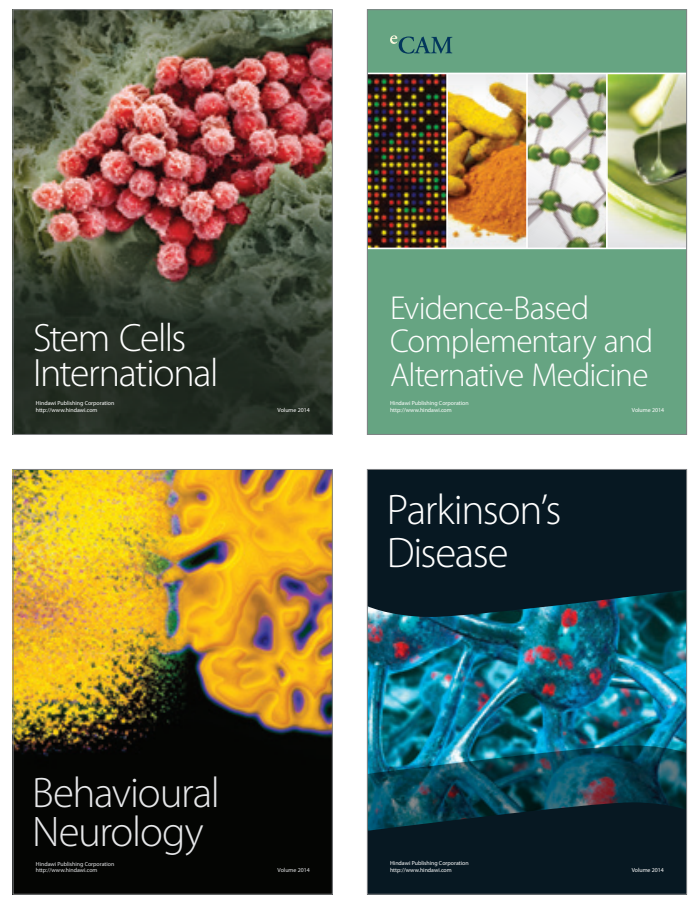
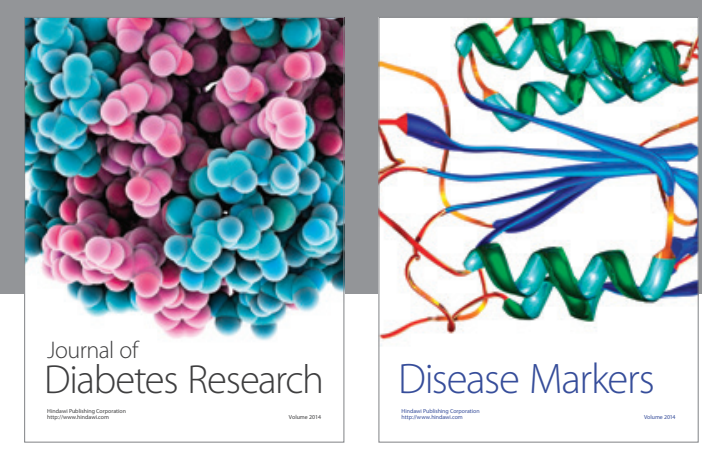

Disease Markers
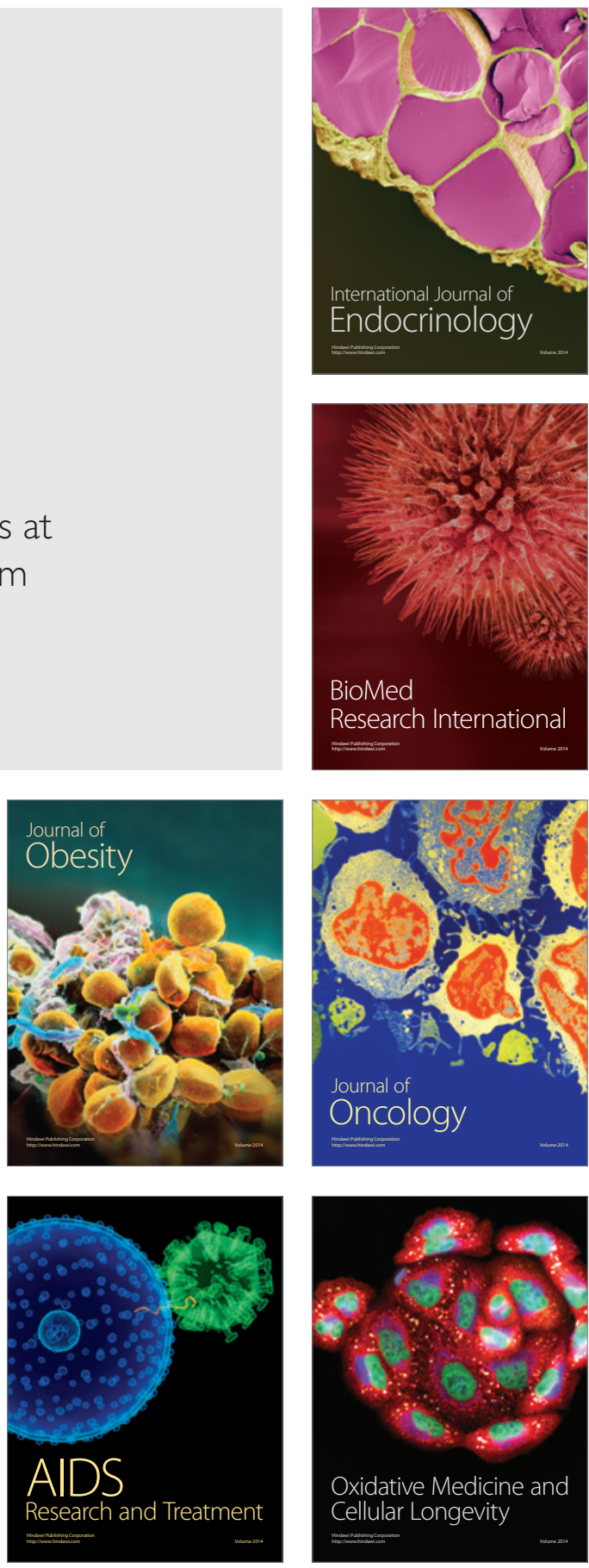